\title{
Patient-reported outcomes from a randomized phase III trial of sarilumab monotherapy versus adalimumab monotherapy in patients with rheumatoid arthritis
}

Vibeke Strand ${ }^{1}$, Laure Gossec ${ }^{2,3}$, Clare W. J. Proudfoot ${ }^{4,9}$, Chieh-I Chen ${ }^{5 *}$, Matthew Reaney ${ }^{4}$, Sophie Guillonneau ${ }^{6}$, Toshio Kimura ${ }^{5}$, Janet van Adelsberg ${ }^{5,10}$, Yong Lin ${ }^{7}$, Erin K. Mangan ${ }^{5}$, Hubert van Hoogstraten ${ }^{7}$

and Gerd R. Burmester ${ }^{8}$

\begin{abstract}
Background: The phase III MONARCH randomized controlled trial (NCT02332590) demonstrated that in patients with rheumatoid arthritis (RA), sarilumab (anti-interleukin-6 receptor monoclonal antibody) monotherapy is superior to adalimumab monotherapy in reducing disease activity and signs and symptoms of RA, as well as in improving physical function, with similar rates of adverse and serious adverse events. We report the effects of sarilumab versus adalimumab on patient-reported outcomes (PROs).

Methods: Patients with active RA intolerant of, or inadequate responders to, methotrexate were randomized to sarilumab $200 \mathrm{mg}$ plus placebo every 2 weeks (q2w; $n=184)$ or adalimumab $40 \mathrm{mg}$ plus placebo q2w $(n=185)$. Dose escalation to weekly administration of adalimumab or matching placebo was permitted at week 16. PROs assessed at baseline and weeks 12 and 24 included patient global assessment of disease activity (PtGA), pain and morning stiffness visual analogue scales (VASs), Health Assessment Questionnaire Disability Index (HAQ-DI), 36-item Short Form Health Survey (SF-36), Functional Assessment of Chronic Illness Therapy-Fatigue (FACIT-F), Rheumatoid Arthritis Impact of Disease (RAID), and rheumatoid arthritis-specific Work Productivity Survey (WPS-RA). Betweengroup differences in least-squares mean (LSM) changes from baseline were analyzed. $p<0.05$ was considered significant for PROs in a predefined hierarchy. For PROs not in the hierarchy, nominal $p$ values are provided. Proportions of patients reporting improvements greater than or equal to the minimal clinically important difference (MCID) and achieving normative values were assessed.

(Continued on next page)
\end{abstract}

\footnotetext{
* Correspondence: chieh-i.chen@regeneron.com

${ }^{5}$ Regeneron Pharmaceuticals, Inc., 777 Old Saw Mill River Road, Tarrytown, NY 10591-6707, USA

Full list of author information is available at the end of the article
}

(c) The Author(s). 2018 Open Access This article is distributed under the terms of the Creative Commons Attribution 4.0 International License (http://creativecommons.org/licenses/by/4.0/), which permits unrestricted use, distribution, and reproduction in any medium, provided you give appropriate credit to the original author(s) and the source, provide a link to the Creative Commons license, and indicate if changes were made. The Creative Commons Public Domain Dedication waiver (http://creativecommons.org/publicdomain/zero/1.0/) applies to the data made available in this article, unless otherwise stated. 
(Continued from previous page)

Results: At week 24, sarilumab treatment resulted in significantly greater LSM changes from baseline than adalimumab monotherapy in HAQ-DI $(p<0.005)$, PtGA $(p<0.001)$, pain VAS $(p<0.001)$, and SF-36 Physical Component Summary (PCS) $(p<0.001)$. Greater LSM changes were reported for sarilumab than for adalimumab in RAID (nominal $p<0.001$ ), morning stiffness VAS (nominal $p<0.05$ ), and WPS-RA (nominal $p<0.005$ ). Between-group differences in FACIT-F and SF-36 Mental Component Summary (MCS) were not significant. More patients reported improvements greater than or equal to the MCID in HAQ-DI (nominal $p<0.01$ ), RAID (nominal $p<0.01$ ), SF-36 PCS (nominal $p<0.005$ ), and morning stiffness (nominal $p<0.05$ ), as well as greater than or equal to the normative values in HAQ-DI $(p<0.05)$, with sarilumab versus adalimumab.

Conclusions: In parallel with the clinical efficacy profile previously reported, sarilumab monotherapy resulted in greater improvements across multiple PROs than adalimumab monotherapy.

Trial registration: ClinicalTrials.gov, NCT02332590. Registered on 5 January 2015.

Keywords: Sarilumab, Adalimumab, Biologic disease-modifying antirheumatic drugs, Rheumatoid arthritis, Patient-reported outcomes

\section{Background}

Interleukin-6 (IL-6) signaling plays a key role in mediating the underlying disease pathophysiology and clinical manifestations of rheumatoid arthritis (RA), including pain and fatigue [1-5]. Sarilumab is an investigational novel human immunoglobulin G1 (IgG1) monoclonal antibody that inhibits IL-6-mediated signaling by selectively binding to soluble and membrane-bound IL- 6 receptor $\alpha[6]$.

Patients report a significant number of adverse events (AEs) associated with conventional synthetic diseasemodifying antirheumatic drugs (csDMARDs), particularly with methotrexate (MTX) [7, 8]. Consequently, at least $30 \%$ of patients with RA using biologic DMARDs (bDMARDs) do not use concomitant background therapy, highlighting the importance of bDMARD monotherapy as a therapeutic option $[9,10]$. As previously reported, sarilumab in combination with csDMARDs reduces disease activity and improves patient-reported outcomes (PROs) with a manageable safety and tolerability profile consistent with IL-6 receptor blockade $[6,11-13]$. The superior efficacy of sarilumab monotherapy in comparison with adalimumab monotherapy was shown in the phase III, multicenter, randomized controlled trial (RCT) MONARCH (NCT02332590) [14]. Rates of AEs and serious AEs observed in MONARCH were similar between treatment groups. Although neutropenia was more common with sarilumab, infection rates were comparable between groups [14].

PROs supplement physician-reported clinical assessments and acute-phase reactant measurements, and they present a more complete understanding of disease, treatment, and treatment impact on patients. Using the American College of Rheumatology (ACR) core dataset alone to define disease activity and treatment benefit does not account for other disease symptoms that are important to patients with RA or for the significant physical, social, and psychological impacts of RA on a patient's daily life and functioning [15-19]. Quantifying fatigue, the effect of RA symptoms on participation (work within and outside the home, family, and social and leisure activities), and ultimately on broad health status or health-related quality of life (HRQOL), is vital for a comprehensive evaluation of RA treatments such as sarilumab [20]. PROs, measured by validated and reliable instruments in appropriately designed trials, offer a means to obtain these data in a clinically meaningful way [21]. This paper reports our comparison of PROs of patients with active RA who received sarilumab monotherapy vs. adalimumab monotherapy.

\section{Methods}

\section{Study design and patient population}

Details of the MONARCH trial have been published previously [14]. Briefly, patients (aged $\geq 18$ years) with active RA who were either intolerant of or inadequate responders (IR) to an MTX dose of $10-25 \mathrm{mg} / \mathrm{wk}$, or $6-$ $25 \mathrm{mg} / \mathrm{wk}$ for patients within the Asia-Pacific region, or considered inappropriate for MTX treatment by investigator judgment were eligible for inclusion. Active RA was defined as at least six swollen and at least eight tender joints, high-sensitivity C-reactive protein $\geq 8 \mathrm{mg} / \mathrm{L}$ or erythrocyte sedimentation rate (ESR) $\geq 28 \mathrm{~mm} / \mathrm{h}$, and 28-joint Disease Activity Score (DAS28)-ESR $>5.1$, with disease duration $\geq 3$ months. Patients were randomized to receive sarilumab $200 \mathrm{mg}$ plus placebo every 2 weeks (q2w) or adalimumab $40 \mathrm{mg}$ plus placebo $\mathrm{q} 2 \mathrm{w}$, administered subcutaneously for 24 weeks. After week 16, dose escalation to weekly administration of adalimumab or matching placebo was permitted for patients who did 
not achieve $\geq 20 \%$ improvement in tender and swollen joint counts. The protocol was approved by appropriate ethics committees/institutional review boards, and all patients provided written consent prior to study participation. The trial was conducted in compliance with institutional review board regulations, the International Conference on Harmonisation Guidelines for Good Clinical Practice, and the Declaration of Helsinki.

\section{Patient-reported outcomes}

PROs included patient global assessment of disease activity (PtGA) [22], pain [22] (both evaluated using a 0 - to $100-\mathrm{mm}$ visual analogue scale [VAS]), and Health Assessment Questionnaire Disability Index (HAQ-DI) to measure physical functioning [22], all of which were included as part of the ACR core set. The 36-item Short Form Health Survey (SF-36) measures health status (or HRQOL) [23] and assesses eight domains on a scale of $0-100$, with higher scores indicating better health status: physical functioning (PF), role physical $(\mathrm{RP})$, bodily pain $(\mathrm{BP})$, general health $(\mathrm{GH})$ perceptions, vitality (VT), social functioning (SF), role emotional $(\mathrm{RE})$, and mental health $(\mathrm{MH})$. These domains are also combined into Physical Component Summary (PCS) and Mental Component Summary (MCS) scores. Other PROs included the Functional Assessment of Chronic Illness Therapy-Fatigue (FACIT-F) scale [24]; morning stiffness, measured by its severity on a $0-\mathrm{mm}$ (no problem) to $100-\mathrm{mm}$ (major problem) VAS [25]; the Rheumatoid Arthritis Impact of Disease (RAID) questionnaire [26]; and the RA-specific Work Productivity Survey (WPS-RA) [27]. The RAID is a composite measure based on seven domains (pain, functional disability, fatigue, physical and emotional well-being, quality of sleep, and coping) scored on 0-10 numerical rating scales, with lower scores indicative of less disease impact [26]. The WPS-RA consists of nine items assessing employment status, absenteeism (days missed), presenteeism (days with work productivity reduced by $\geq 50 \%$ ), rate of RA interference in work within and outside the home $(0=$ no interference to $10=$ complete interference), and participation measured as days missed in family, leisure, and social activities [27]. All PROs were assessed at baseline and weeks 12 and 24 .

\section{Statistical analyses}

Analyses were based on the intention-to-treat (ITT) population. For continuous endpoints, between-group differences in changes from baseline were determined using a mixed-model approach for repeated measures, with treatment, visit, treatment-by-visit interaction, and region as fixed effects and the corresponding baseline PRO scores as continuous covariates. Data collected after patients had their dose of adalimumab (or matching placebo) increased were included in the primary analysis; data collected after permanent treatment discontinuation of either sarilumab or adalimumab were excluded. Statistical significance could be claimed for those outcomes above the break in the predefined statistical analysis hierarchy, which included changes from baseline to week 24 in HAQ-DI and SF-36 PCS scores. Because PtGA and pain VAS were part of the ACR20/ $50 / 70$ core set, a prespecified secondary efficacy endpoint, they were also considered above the hierarchy break. For endpoints below the hierarchy break or not included in the hierarchy, $p$ values are considered nominal. Because the WPS-RA consists of independent items, O'Brien's global test was first used to determine overall significance at week 24 prior to further evaluation.

The proportion of patients reporting clinically meaningful improvements, such as meeting or exceeding published values for minimal clinically important differences (MCIDs) ("responders"), was evaluated for each PRO. These were prespecified for HAQ-DI $(\geq 0.22$ units [28] and $\geq 0.3$ units $[29,30])$ and applied post hoc for PtGA, pain and morning stiffness VAS ( $\geq 10$ units [31, 32]), SF-36 $(\geq 2.5$ units for PCS and MCS and $\geq 5$ units for domains [33]), FACIT-F ( $\geq 4$ units [24]), and RAID ( $\geq 3$ units [34]). Patients who discontinued treatment were considered nonresponders in the analyses. Between-group differences in proportions were analyzed using the Cochran-MantelHaenszel test stratified by region. Additional post hoc analyses included the proportion of patients reporting scores greater than or equal to normative values for the $U$. S. general population in HAQ-DI $(<0.05)$ [35], FACIT-F $(\geq 40.1)$ [36], SF-36 PCS and MCS $(\geq 50)$, and age- and sex-matched SF-36 domain scores at week 24.

\section{Results}

\section{Patient demographics and baseline characteristics}

Detailed patient demographics and baseline disease characteristics have been described previously [14]. In brief, the ITT population consisted of 369 patients (sarilumab, $n=184$; adalimumab, $n=185$ ). Baseline characteristics as well as disease and treatment history were generally balanced between treatment groups (Table 1). The mean (SD) age of participants was 52.2 (12.3) years; most were female (83\%) and white (91\%). Mean (SD) durations of RA were 8.1 (8.1) years in the sarilumab group and 6.6 (7.8) years in the adalimumab group; mean (SD) baseline DAS28-ESR was $6.8(0.8)$ in both groups. Baseline PRO scores were generally balanced between treatment groups (Table 2). At baseline, 78 (42.6\%) patients in the sarilumab group and 69 (37.5\%) in the adalimumab group were employed outside the home. Six patients in the adalimumab group and five patients in the sarilumab group who met protocol criteria received dose escalations of weekly administration of adalimumab 
Table 1 Patient demographics and disease characteristics

\begin{tabular}{|c|c|c|}
\hline & Sarilumab SC 200 mg q2w ( $n=184)$ & Adalimumab SC $40 \mathrm{mg}$ q2w $(n=185)$ \\
\hline \multicolumn{3}{|l|}{ Demographics } \\
\hline Age, years, mean $\pm S D$ & $50.9 \pm 12.6$ & $53.6 \pm 11.9$ \\
\hline Female sex, $n(\%)$ & $157(85.3)$ & $150(81.1)$ \\
\hline Race, white, $n(\%)$ & $171(92.9)$ & $164(88.6)$ \\
\hline Weight, $\mathrm{kg}$, mean \pm SD & $72.3 \pm 16.5$ & $71.8 \pm 17.8$ \\
\hline $\mathrm{BMI}, \mathrm{kg} / \mathrm{m}^{2}$, mean $\pm \mathrm{SD}$ & $27.1 \pm 5.6$ & $27.3 \pm 6.5$ \\
\hline \multicolumn{3}{|l|}{ Geographic region, $n(\%)^{\mathrm{a}}$} \\
\hline 1 & $61(33.2)$ & $62(33.5)$ \\
\hline 2 & $36(19.6)$ & $35(18.9)$ \\
\hline 3 & $87(47.3)$ & $88(47.6)$ \\
\hline \multicolumn{3}{|l|}{ Disease and treatment history } \\
\hline Duration of RA, years, mean $\pm S D$ & $8.1 \pm 8.1$ & $6.6 \pm 7.8$ \\
\hline Rheumatoid factor-positive, $n(\%)^{\mathrm{b}}$ & $119(66.9)$ & $116(64.8)$ \\
\hline Anti-CCP autoantibody-positive, $n(\%)^{c}$ & $134(75.3)$ & $138(76.7)$ \\
\hline \multicolumn{3}{|l|}{ Number of prior csDMARDs, $n(\%)$} \\
\hline 0 & 0 & 0 \\
\hline 1 & $83(45.1)$ & $88(47.6)$ \\
\hline 2 & $57(31.0)$ & $58(31.4)$ \\
\hline$\geq 3$ & $44(23.9)$ & $39(21.1)$ \\
\hline \multicolumn{3}{|l|}{ Prior csDMARDs other than MTX, $n(\%)^{d}$} \\
\hline Sulfasalazine & $59(32.1)$ & $44(23.8)$ \\
\hline Leflunomide & $42(22.8)$ & $45(24.3)$ \\
\hline Hydroxychloroquine & $41(22.3)$ & $43(23.2)$ \\
\hline Prior csDMARDs in combination with MTX, $n(\%)$ & $35(19.0)$ & $44(23.8)$ \\
\hline \multicolumn{3}{|l|}{ Reason for stopping MTX, $n(\%)$} \\
\hline Inadequate responder & $97(52.7)$ & $103(55.7)$ \\
\hline Intolerant & $87(47.3)$ & $81(43.8)$ \\
\hline Inappropriate for continued treatment & 0 & $1(0.5)$ \\
\hline Concomitant oral corticosteroids, $n(\%)$ & $98(53.3)$ & $104(56.2)$ \\
\hline \multicolumn{3}{|l|}{ Disease activity, mean \pm SD } \\
\hline DAS28-ESR & $6.8 \pm 0.8$ & $6.8 \pm 0.8$ \\
\hline DAS28-CRPe & $6.0 \pm 0.9$ & $6.0 \pm 0.9$ \\
\hline Swollen joint count (66 assessed) ${ }^{e}$ & $18.6 \pm 10.7$ & $17.5 \pm 10.3$ \\
\hline Tender joint count (68 assessed) $)^{\mathrm{e}}$ & $28.0 \pm 13.2$ & $26.7 \pm 13.6$ \\
\hline $\mathrm{CDAl}^{\mathrm{e}}$ & $43.6 \pm 12.1$ & $42.4 \pm 12.0$ \\
\hline$E S R, m m / h^{e}$ & $46.5 \pm 21.8$ & $47.5 \pm 23.2$ \\
\hline$C R P, \mathrm{mg} / \mathrm{L}^{\mathrm{e}}$ & $17.4 \pm 21.3$ & $24.1 \pm 31.0$ \\
\hline
\end{tabular}

Abbreviations: BMI Body mass index, CCP Cyclic citrullinated peptide, CDAl Clinical Disease Activity Index, CRP, C-reactive protein, CsDMARD Conventional synthetic disease-modifying antirheumatic drug, DAS28 28-joint Disease Activity Score, ESR Erythrocyte sedimentation rate, MTX Methotrexate, q2w Every 2 weeks, RA Rheumatoid arthritis, SC Subcutaneous

${ }^{a}$ Region 1 (Western countries): Czech Republic, Germany, Hungary, Israel, Spain, United States. Region 2 (South America): Chile, Peru. Region 3 (rest of the world): Poland, South Africa, South Korea, Romania, Russia, Ukraine

${ }^{\mathrm{b}}$ Adalimumab group, $n=179$; sarilumab group, $n=178$

'Adalimumab group, $n=180$; sarilumab group, $n=178$

Included if used in $>5 \%$ of the population

${ }^{\mathrm{e}}$ Higher numbers represent more severe disease 
Table 2 Patient-reported outcome scores at baseline (intention-to-treat population)

\begin{tabular}{|c|c|c|}
\hline Patient-reported outcome & Sarilumab SC 200 mg q2w $(n=184)$ & Adalimumab SC $40 \mathrm{mg}$ q2w $(n=185)$ \\
\hline$\overline{\mathrm{HAQ}-\left.\mathrm{DI}\right|^{\mathrm{a}}}$ & $1.6(0.55)$ & $1.6(0.64)$ \\
\hline Pain VAS ${ }^{b}$ & $71.6(18.65)$ & $71.4(18.96)$ \\
\hline$P t G A^{b}$ & $68.0(17.49)$ & $67.8(18.41)$ \\
\hline \multicolumn{3}{|l|}{$S F-36^{c}$} \\
\hline PCS & $30.7(6.15)$ & $31.4(6.59)$ \\
\hline MCS & $36.7(10.67)$ & $37.1(11.83)$ \\
\hline Physical functioning & $33.3(20.04)$ & $35.7(21.73)$ \\
\hline Role physical & $34.4(18.88)$ & $34.2(20.08)$ \\
\hline Bodily pain & $26.7(14.75)$ & $28.4(16.55)$ \\
\hline General health & $34.4(15.64)$ & $36.1(16.21)$ \\
\hline Vitality & $33.4(16.42)$ & $35.5(17.87)$ \\
\hline Social functioning & $46.5(23.23)$ & $47.4(26.03)$ \\
\hline Role emotional & $47.1(24.44)$ & $47.4(27.25)$ \\
\hline Mental health & $49.0(18.52)$ & $50.5(19.69)$ \\
\hline FACIT-F ${ }^{d}$ & $23.6(9.01)$ & $24.0(10.31)$ \\
\hline Morning stiffness VAS ${ }^{b}$ & $70.8(18.99)$ & $68.0(21.37)$ \\
\hline RAID score $(0-10)^{e}$ & $6.7(1.72)$ & $6.4(2.03)$ \\
\hline \multicolumn{3}{|l|}{ WPS-RA } \\
\hline Employed outside the home, $n$ (\%) & $78(42.6)$ & $69(37.5)$ \\
\hline Work days missed & $2.5(5.26)$ & $2.0(5.11)$ \\
\hline Days with work productivity reduced by $\geq 50 \%$ & $5.8(7.03)$ & $4.9(7.66)$ \\
\hline Interference with work productivity ${ }^{f}$ & $5.6(2.62)$ & $4.8(2.98)$ \\
\hline Housework days missed & $8.7(8.14)$ & $7.3(9.06)$ \\
\hline Days with household productivity reduced by $\geq 50 \%$ & $10.0(8.78)$ & $9.4(9.68)$ \\
\hline Interference with household productivity & $6.5(2.60)$ & $6.3(2.88)$ \\
\hline Days with family, social, or leisure activities missed & $5.4(7.84)$ & $5.6(8.51)$ \\
\hline Days with outside help hired & $5.2(8.43)$ & $4.6(8.57)$ \\
\hline
\end{tabular}

Abbreviations: FACIT-F Functional Assessment of Chronic Illness Therapy-Fatigue; HAQ-DI Health Assessment Questionnaire Disability Index, MCS Mental Component Summary, PCS Physical Component Summary, PtGA Patient global assessment of disease activity, q2w Every 2 weeks, RAID Rheumatoid Arthritis Impact of Disease, SC Subcutaneous, SF-36 36-item Short Form Health Survey, VAS Visual analogue scale, WPS-RA Rheumatoid arthritis-specific Work Productivity Survey

a Scale range, 0-3; lower scores represent less difficulty with physical functioning

${ }^{\mathrm{b}} \mathrm{S}$ cale range, 0-100; lower scores indicate better outcomes

'Scale range, 0-100; higher scores represent less impaired physical/mental health status

${ }^{\mathrm{d}} \mathrm{Scale}$ range, 0-52; higher scores represent less fatigue

escale range, 0-10; higher scores indicate a greater (negative) impact of RA

${ }^{\mathrm{f}} \mathrm{S}$ cale range, $0=$ no interference to $10=$ complete interference

(adalimumab group) or matching placebo (sarilumab group). The study was completed by most patients (sarilumab, 90\%; adalimumab, 84\%), with AEs being the most common cause of discontinuation.

\section{Changes from baseline at weeks 12 and 24}

Table 3 summarizes least-squares mean (LSM) changes in PROs reported with sarilumab $200 \mathrm{mg}$ q2w and adalimumab 40 mg q2w from baseline to week 24. Top-line results for HAD-QI, PtGA, SF-36, FACIT-F, and pain VAS have been reported previously [14], but they are presented here in detail for completeness. At week 24, both sarilumab and adalimumab treatment resulted in improvements in all PROs. LSM changes from baseline in HAQ-DI $(p<0.005)$, pain VAS $(p<0.001)$, PtGA $(p<0.001)$, and SF-36 PCS scores $(p<0.001)$ were significantly greater with sarilumab than with adalimumab; however, the SF-36 MCS scores were not statistically different $(p=0.332)$. At week 24, improvements in four of eight SF-36 domains were significantly greater with sarilumab than with adalimumab (PF and BP, both $p<0.005$; RP and SF, both 
Table 3 Change from baseline to week 24 with sarilumab 200 mg or adalimumab 40 mg every 2 weeks

\begin{tabular}{|c|c|c|c|c|}
\hline \multirow[b]{2}{*}{ Patient-reported outcome } & \multicolumn{2}{|c|}{ LSM (SE) change from baseline to Week 24} & \multirow[b]{2}{*}{$\begin{array}{l}\text { LSM between-group difference } \\
\qquad(95 \% \mathrm{CI})\end{array}$} & \multirow[b]{2}{*}{$p$-value ${ }^{\dagger}$} \\
\hline & $\begin{array}{l}\text { Sarilumab SC } \\
200 \mathrm{mg} \mathrm{q2w} \\
(\mathrm{n}=184)\end{array}$ & $\begin{array}{l}\text { Adalimumab SC } \\
\begin{array}{c}40 \mathrm{mg} \mathrm{q} 2 \mathrm{w} \\
(\mathrm{n}=185)\end{array}\end{array}$ & & \\
\hline HAQ-DI & $-0.61(0.05)$ & $-0.43(0.05)$ & $-0.18(-0.31,-0.06)$ & $<0.005$ \\
\hline Pain VAS & $-36.19(1.78)$ & $-27.41(1.80)$ & $-8.78(-13.66,-3.90)$ & $<0.001$ \\
\hline PtGA & $-33.30(1.73)$ & $-24.82(1.75)$ & $-8.48(-13.24,-3.72)$ & $<0.001$ \\
\hline \multicolumn{5}{|l|}{ SF-36 component summaries } \\
\hline SF-36: PCS & $8.74(0.56)$ & $6.09(0.56)$ & $2.65(1.15,4.15)$ & $<0.001$ \\
\hline SF-36: MCS & $7.86(0.77)$ & $6.83(0.77)$ & $1.04(-1.06,3.13)$ & 0.332 \\
\hline \multicolumn{5}{|l|}{ SF-36 individual domains } \\
\hline Physical functioning & $22.38(1.64)$ & $15.01(1.65)$ & $7.37(2.91,11.83)$ & $<0.005$ \\
\hline Role physical & $20.80(1.61)$ & $16.23(1.63)$ & $4.57(0.18,8.96)$ & $<0.050$ \\
\hline Bodily pain & $25.69(1.46)$ & $19.40(1.47)$ & $6.28(2.32,10.25)$ & $<0.005$ \\
\hline General health & $13.96(1.18)$ & $11.05(1.19)$ & $2.91(-0.30,6.12)$ & 0.076 \\
\hline Vitality & $17.95(1.42)$ & $14.39(1.43)$ & $3.56(-0.31,7.43)$ & 0.071 \\
\hline Social functioning & $21.41(1.81)$ & $15.04(1.83)$ & $6.37(1.43,11.30)$ & $<0.050$ \\
\hline Role emotional & $18.04(1.79)$ & $14.10(1.81)$ & $3.94(-0.94,8.82)$ & 0.113 \\
\hline Mental health & $14.29(1.31)$ & $13.26(1.32)$ & $1.02(-2.54,4.58)$ & 0.572 \\
\hline FACIT-F & $10.18(0.70)$ & $8.41(0.71)$ & $1.77(-0.14,3.67)$ & 0.069 \\
\hline Morning stiffness VAS & $-35.08(1.95)$ & $-29.29(1.97)$ & $-5.80(-11.10,-0.50)$ & $<0.050$ \\
\hline RAID & $-3.08(0.17)$ & $-2.30(0.17)$ & $-0.78(-1.23,-0.32)$ & $<0.001$ \\
\hline WPS-RA (global) ${ }^{\ddagger}$ & N/A & $\mathrm{N} / \mathrm{A}$ & N/A & $<0.005$ \\
\hline Work days missed§ & $-0.28(0.55)$ & $0.05(0.61)$ & $-0.33(-1.86,1.20)$ & 0.667 \\
\hline $\begin{array}{l}\text { Days with work productivity } \\
\text { reduced by } \geq 50 \% \S\end{array}$ & $-3.74(0.46)$ & $-3.50(0.53)$ & $-0.24(-1.53,1.05)$ & 0.712 \\
\hline $\begin{array}{l}\text { Interference with work } \\
\text { productivity" }\end{array}$ & $-2.90(0.31)$ & $-2.58(0.35)$ & $-0.32(-1.21,0.57)$ & 0.475 \\
\hline Housework days missed & $-5.49(0.40)$ & $-4.22(0.41)$ & $-1.28(-2.36,-0.19)$ & $<0.050$ \\
\hline $\begin{array}{l}\text { Days with household productivity } \\
\text { reduced by } \geq 50 \%\end{array}$ & $-6.70(0.45)$ & $-4.87(0.45)$ & $-1.83(-3.04,-0.62)$ & $<0.005$ \\
\hline $\begin{array}{l}\text { Interference with household } \\
\text { productivity }\end{array}$ & $-3.32(0.21)$ & $-2.66(0.21)$ & $-0.66(-1.23,-0.09)$ & $<0.050$ \\
\hline $\begin{array}{l}\text { Days with family, social, or } \\
\text { leisure activities missed }\end{array}$ & $-4.14(0.37)$ & $-3.33(0.38)$ & $-0.82(-1.83,0.19)$ & 0.111 \\
\hline Days with outside help hired & $-3.43(0.40)$ & $-2.57(0.40)$ & $-0.86(-1.94,0.22)$ & 0.120 \\
\hline
\end{tabular}

Abbreviations: ACR American College of Rheumatology; FACIT-F Functional Assessment of Chronic Illness Therapy-Fatigue; HAQ-DI Health Assessment Questionnaire Disability Index; LSM Least-squares mean; MCS Mental Component Summary; N/A Not applicable; PCS Physical Component Summary; PtGA Patient global assessment of disease activity; q2w Every 2 weeks; RAID Rheumatoid Arthritis Impact of Disease; SC Subcutaneous; SF-36 36-item Short Form Health Survey; VAS Visual analogue scale; WPS-RA Rheumatoid arthritis-specific Work Productivity Survey

a LSM between-group differences (sarilumab vs. adalimumab). All $p$ values below the solid line are nominal (see the Methods section of text)

${ }^{\mathrm{b}} \mathrm{Global}$ test for the change from baseline in the eight WPS-RA scores

'Number of patients included in the analysis for this element of the WPS-RA score: adalimumab group, $n=60$; sarilumab group, $n=70$

${ }^{\mathrm{d}}$ Number of patients included in this element of the WPS-RA score: adalimumab group, $n=57$; sarilumab group, $n=68$

$p<0.05$ ) (Fig. 1 and Table 3). At week 24, LSM changes in

FACIT-F were not statistically different $(p=0.069)$

(Table 3).
At week 24, improvements in morning stiffness VAS were greater with sarilumab treatment than with adalimumab (nominal $p<0.05$ ), as were improvements in total 


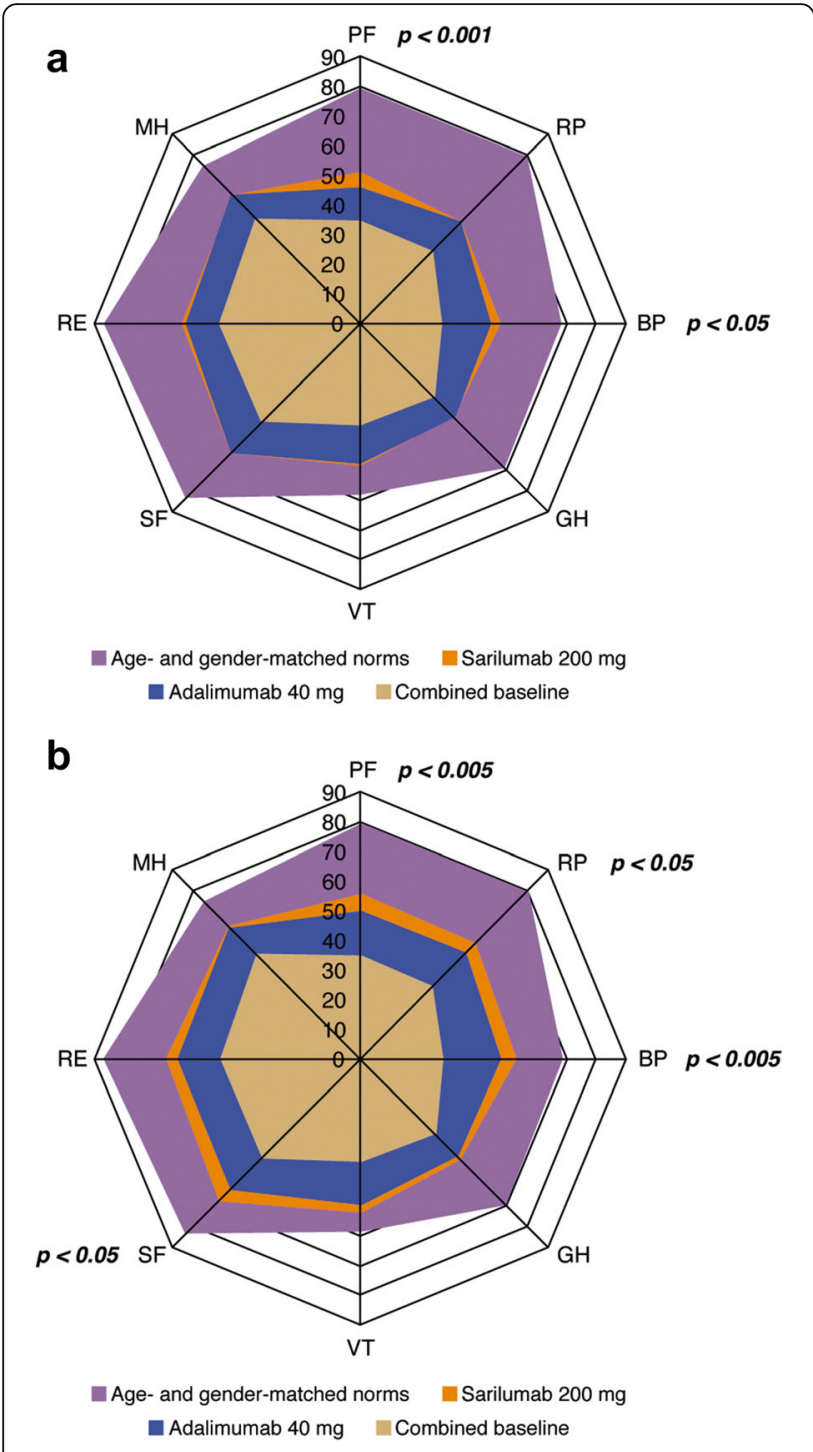

Fig. 1 Baseline and posttreatment scores at week 12 (a) and week 24 (b) across all 36-item Short Form Health Survey domains compared with age- and sex-matched U.S. general population norms. BP Body pain, GH General health, MH Mental health, PF Physical functioning, RE Role emotional, RP Role physical, SF Social functioning, VT Vitality. $p$ Values show the least-squares mean between-group difference in the change from baseline. $p$ Values provided for week 12 are nominal. Because combined baseline scores are presented, change from baseline for each group cannot be inferred from the figure alone

RAID score (nominal $p<0.001$ ) and all seven individual RAID components (all nominal $p<0.05$ ), with greatest effects observed in the pain and functional disability domains (Additional file 1: Table S1). At week 24, global testing indicated that sarilumab treatment resulted in greater overall improvement in WPS-RA than adalimumab (nominal $p<0.005$ ), including more reductions in the number of household work days missed due to RA (nominal $p<0.05$ ), days in which household productivity was reduced by $\geq 50 \%$ (nominal $p<0.005$ ), and the rate of RA interference with household work (nominal $p<0.05$ ).

LSM changes reported at week 12 are summarized in Additional file 1: Table S2. Similar results were reported at week 12 for all PROs; however, LSM between-group differences increased over time, with greater differences reported at week 24 than at week 12 for all PROs.

As part of the study, patients who did not achieve a $\geq 20 \%$ improvement in tender and swollen joint counts were permitted to escalate their dose to weekly administration of adalimumab or matching placebo. A total of five patients in the sarilumab group and six patients in the adalimumab group met the requirements for dose escalation. A sensitivity analysis was conducted where all data after treatment discontinuation or adalimumab (or matching placebo) dose increase were set to missing and a multiple imputation approach was used. A statistically significant difference in favor of sarilumab compared with adalimumab was observed, which was similar with that in the primary analysis.

\section{Responder analysis}

At week 24, improvements greater than or equal to the MCID were reported by a greater percentage of patients with sarilumab than adalimumab for HAQ-DI (67.4\% vs. 54.1\%; nominal $p<0.01[\geq 0.22$ units] and $62.0 \%$ vs. 47.6\%; nominal $p<0.01$ [ $\geq 0.3$ units]), SF-36 PCS score ( $68.5 \%$ vs. $54.1 \%$; nominal $p<0.005)$, RAID ( $43.5 \%$ vs. 29.7\%; nominal $p<0.01)$, and morning stiffness $(73.9 \%$ vs. $62.2 \%$; nominal $p<0.05$ ) (Fig. 2).

As shown in Fig. 1, mean baseline scores for SF-36 domains were substantially below age- and sex-matched norms. The percentages of patients who reported normative values at baseline in HAQ-DI, FACIT-F, and individual SF-36 domains ranged from $1.1 \%$ for HAQ-DI and the SF-36 BP domain to $15.1 \%$ for SF-36 MH domain (Fig. 3). At week 24, the percentages of patients reporting scores greater than or equal to normative values in HAQ-DI, FACIT-F, and SF-36 PCS and MCS and all individual SF-36 domains increased with both sarilumab and adalimumab, with numerically greater increases reported with sarilumab than with adalimumab (Fig. 3).

\section{Discussion}

These results from the MONARCH study show that sarilumab monotherapy is superior to adalimumab monotherapy according to a number of patient-reported endpoints, including physical function. Improvements were demonstrated by week 12, and between-group differences increased over time, despite the allowance of adalimumab or matched placebo (but not sarilumab) 

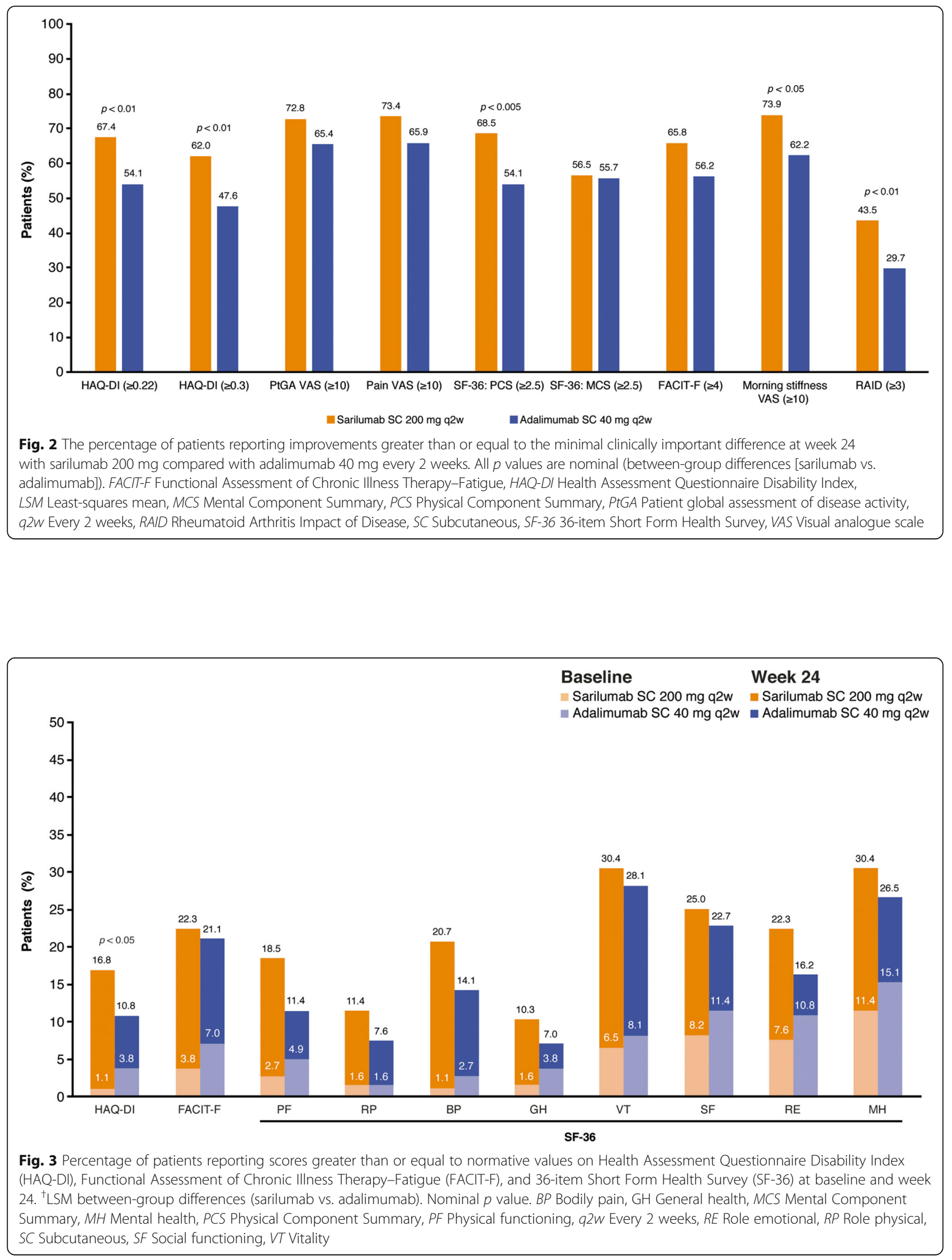
dose escalation in patients with poor responses. Results from these PRO analyses support the clinical efficacy data previously reported [14].

As in previous clinical trials of sarilumab and adalimumab [11, 13, 37], baseline PRO scores indicate a substantial impairment of general health status, physical function, and participation when compared with an ageand sex-matched U.S. general population. Considerable improvements in PROs were reported after treatment with both sarilumab and adalimumab. This is consistent with previous RCTs of sarilumab administered in combination with csDMARDs in MTX-IR and tumor necrosis factor inhibitor (TNFi)-IR RA populations [11, 13] and of adalimumab administered in combination with MTX in patients with early RA or as a monotherapy in patients with active RA who are intolerant of or inappropriate for continued MTX treatment [37, 38]. Notably, the proportion of patients reporting normative values in HAQ-DI, FACIT-F, and SF-36 PCS and MCS and all individual SF-36 domains was substantially increased with both therapies, with numerically greater increases reported with sarilumab than with adalimumab. These data indicate that attainment of normative values is now a reasonable goal for RA therapy.

Compared with adalimumab, sarilumab resulted in significantly greater improvements in PtGA, physical function, and indicators of health status (HAQ-DI, SF-36 PCS) and pain. Sarilumab monotherapy also resulted in greater improvements in RAID than adalimumab monotherapy, providing further evidence of the broad benefits of sarilumab monotherapy in reducing the impact of RA on patients' lives. RAID is a relatively new disease-specific measure that provides a weighted profile of seven patientvalued domains: pain, functional disability, fatigue, sleep, physical/emotional well-being, and coping [26]. Improvements in RAID with sarilumab monotherapy are consistent with those previously reported with sarilumab plus csDMARDs in a TNFi-IR RA population [13].

The impact of fatigue is a key consideration for patients with active RA [39, 40]. Improvements in fatigue based on FACIT-F, the VT domain of SF-36, and the fatigue domain of RAID were reported in both the sarilumab and adalimumab groups. Improvements in the fatigue domain of RAID, FACIT-F, and SF-36 VT were numerically greater with sarilumab than with adalimumab; however, between-group differences in FACIT-F, which was part of the hierarchy, did not reach statistical significance. Morning stiffness has also been shown to have a significant impact on the lives and well-being of patients with RA and can result in frustration, distress, and absenteeism [41]. Both sarilumab and adalimumab resulted in improvements in morning stiffness [11, 13, 42, 43], with greater improvements with sarilumab than with adalimumab.
WPS-RA scores demonstrated that the interference of RA with work inside and outside the home and participation in family, social, and leisure activities were reduced with both sarilumab and adalimumab. Improvements in the global WPS-RA score were greater with sarilumab than with adalimumab. However, numerical between-group differences in the elements of the score that assess the impact of RA on work outside the home were small, although only $40 \%$ of the study population were employed, which may limit the ability to detect a difference.

The clinical efficacy data from the MONARCH trial are consistent with those of the ADACTA trial, which demonstrated superior clinical efficacy of tocilizumab monotherapy, another IL-6 receptor inhibitor, compared with adalimumab monotherapy, despite the allowance of adalimumab (or matched placebo) dose escalation [38]. However, in ADACTA, between-group differences in HAQ-DI and SF-36 PCS did not reach statistical significance, whereas improvements in SF-36 MCS were greater with tocilizumab than with adalimumab [38]. In MONARCH, sarilumab resulted in statistically significant and clinically meaningful improvements in HAQDI and SF-36 PCS compared with adalimumab, but between-group differences in SF-36 MCS were not significantly different.

PROs are an essential supplement to clinical data and provide a true measurable insight into treatment effects that are not completely assessed by clinical endpoints included in the ACR core set. Key strengths of this head-to-head trial are the wide range of PROs evaluated, including general and specific measures, which allow for a comprehensive evaluation of patient-reported benefits of two different bDMARD monotherapies, and the range of analyses undertaken to understand the level of benefit observed from a patient perspective. One limitation of the study was that several of the PROs were not included in the formal statistical testing hierarchy, which may limit the conclusions that can be made.

\section{Conclusions}

In patients with RA who are unsuitable candidates for treatment with MTX owing to intolerance or inadequate response, treatment with sarilumab monotherapy resulted in greater patient-reported improvements in PtGA, pain, HAQ-DI, SF-36 PCS and PF, RP, BP and SF domain scores, morning stiffness, RAID, and WPS-RA compared with adalimumab monotherapy. Reducing the impact of RA on patients' lives is an important treatment objective, and these data indicate that sarilumab monotherapy may result in better patient-reported benefits than monotherapy with a widely used bDMARD, adalimumab. 


\section{Additional file}

Additional file 1: Table S1. LSM changes in RAID individual domain scores from baseline to week 24 with sarilumab $200 \mathrm{mg}$ or adalimumab 40 mg q2w. Table S2. LSM change from baseline to week 12 with sarilumab $200 \mathrm{mg}$ or adalimumab $40 \mathrm{mg}$ q2w. (DOCX $42 \mathrm{~kb}$ )

\section{Abbreviations}

ACR: American College of Rheumatology; AE: Adverse event: bDMARD: Biologic disease-modifying antirheumatic drug; BP: Bodily pain; CSDMARD: Conventional synthetic disease-modifying antirheumatic drug; DAS28-CRP: 28-Joint Disease Activity Score using C-reactive protein; DAS28-ESR: 28-Joint Disease Activity Score using erythrocyte sedimentation rate; DMARD: Disease-modifying antirheumatic drug; ESR: Erythrocyte sedimentation rate; FACIT-F: Functional Assessment of Chronic Illness Therapy-Fatigue; GH: General health; HAQ-DI: Health Assessment Questionnaire Disability Index; HRQOL: Health-related quality of life; IL-6: Interleukin-6; ITT: Intention to treat; LSM: Least-squares mean; MCID: Minimal clinically important difference; MCS: Mental Component Summary; MH: Mental health; MTX: Methotrexate; PCS: Physical Component Summary; PF: Physical functioning; PRO: Patient-reported outcome; PtGA: Patient global assessment of disease activity; q2w: Every 2 weeks; RA: Rheumatoid arthritis; RAID: Rheumatoid Arthritis Impact of Disease score; RE: Role emotional; RP: Role physical; SF: Social functioning; SF-36: 36-Item Short Form Health Survey; TNFi: Tumor necrosis factor inhibitor; VAS: Visual analogue scale; VT: Vitality; WPS-RA: Rheumatoid arthritis-specific Work Productivity Survey

\section{Acknowledgements}

The authors thank the patients, their families, and all investigators involved in this study. Medical writing support, including developing the outline and initial manuscript draft and incorporation of comments, was provided by Alex Mellors, and editorial support, including formatting, proofreading, and submission, was provided by Sinead Stewart, both of Prime Global Medical Communications, Knutsford, Cheshire, UK, and supported by Sanofi and Regeneron Pharmaceuticals, Inc., according to good publication practice guidelines (http//annals.org/aim/article/2424869/goodpublication-practice-communicating-company-sponsored-medical-researchgpp3). The research sponsor was involved in the study design; the collection, analysis, and interpretation of data; and data checking of information included in the article. However, the authors were responsible for all content and editorial decisions and received no honoraria related to the development of this publication.

\section{Funding}

This research was sponsored by Sanofi and Regeneron Pharmaceuticals, Inc.

\section{Availability of data and materials}

Individual participant data (IPD) and supporting clinical documents are available on request at www.clinicalstudydatarequest.com. In making information available, we continue to protect the privacy of the participants in our clinical trials. Details on data-sharing criteria and the process for requesting access can be found at: www.clinicalstudydatarequest.com.

\section{Authors' contributions}

VS, GRB, JVA, HVH and YL conceptualized and designed the study. GRB, JVA $H v H$, and $Y L$ acquired the data. VS, LG, CWJP, CC, MR, SG, TK, JVA, YL, EKM, $\mathrm{HvH}$, and GRB analyzed and interpreted the data. All authors were involved in the study design and/or in the collection, analysis, and interpretation of the data; the writing of the manuscript; and the decision to submit the manuscript for publication. All authors are responsible for all content and editorial decisions. All authors read and approved the final manuscript.

\section{Ethics approval and consent to participate}

The protocol received approval from the institutional review board and independent ethics committee of the investigational centers and was performed in accordance with the Declaration of Helsinki. All patients provided written consent prior to study participation, and the trial was conducted in compliance with institutional review board regulations, the
International Conference on Harmonisation Guidelines for Good Clinical Practice, and the Declaration of Helsinki. The specific ethical bodies that approved study are as follows: Comité de Ética Científico, S.S.M. Oriente, Chile; Eticka komise, Revmatologickeho ustavu, Czech Republic; EK FN Královské, Vinohrady, FN Kralovske Vinohrady, Czech Republic; Eticka komise, Uherskohradistske nemocnice, a.s., Czech Republic; Ethik-Kommission des Landes Berlin, Landesamt für Gesundheit und Soziales, Berlin, Germany; Medical Research Council, Ethics Committee for Clinical Pharmacology, Hungary; Ethics Committee of Tel Aviv, Sourasky Medical Center, Israel; EC of Sheba Medical Center, The Chaim Sheba Medical Center, Israel; Ethics Committee of Carmel Medical Center, Israel; Seoul National University Hospital, Republic of Korea; Eulji University Hospital, Republic of Korea; Keimyung University, Dongsan Medical Center, Republic of Korea; CE de la asociación benéfica Prisma Carlos Gonzales, Peru; Komisja Bioetyczna przy Okregowej Radzie Lekarskiej WIL, Poland; National Bioethics Committee of Medical Product and Medical Devices, Romania; LEC of the Scientific Research Institute of Rheumatology, Russian Federation; Ethics Board at Ministry of Health of the Russian Federation, Russian Federation; LEC of the Kemerovo State Medical Academy, Russian Federation; LEC of the Saintpetersburg I.I. Dzhanelidze Research Institute, Russian Federation; LEC of Saratov Regional Clinical Hospital, Russian Federation; LEC of 'Applied Medicine', Russian Federation; LEC of the Moscow City Hospital n.a. S. P. Botkin, Russian Federation; LEC of the City Clinical Hospital n.a. M.E. Zhadkevich, Russian Federation; Pharma Ethics (Pty) Ltd., South Africa; CEIC Corporació Sanitària del Parc Taulí, Spain; LEC of the Regional Clinical Hospital n.a. N.I. Pyrogov, Ukraine; LEC of Consultative Diagnostic Center of Pechersky District, Ukraine; LEC of the Ivano-Frankivsk Regional Clinical Hospital, Ukraine; LEC of Lutsk Regional Hospital, Ukraine; LEC of Vinnytsya City Clinical Hospital \#1, Ukraine; LEC of Lviv Regional Clinical Diagnostic Center, Ukraine; LEC Kyiv City Clinical Hospital \#3, Ukraine; LEC of MIHC Regional Clinical Hospital, Ukraine; LEC of Poltava Regional Clinical Hospital n.a. Sklyfosofsky, Ukraine; NRES Committee London - London Bridge National Research Ethics Service, United Kingdom; Chesapeake IRB, United States; Comité de Protection des Personnes Est III Hôpital de Brabois, France; Ethics Committee of Bnei Zion Medical Center Bnei Zion, Israel; Ethics Committee of Rambam Medical Center, Israel; Ajou University Hospital, Republic of Korea; Chungnam National University Hospital, Republic of Korea; Chosun University Hospital, Republic of Korea; Dong-A University Hospital, Republic of Korea; Wits Human Research EC, South Africa; Dartmouth Medical School IRB, United States.

\section{Competing interests}

VS is a consultant for AbbVie, Amgen, AstraZeneca, BMS, Boehringer Ingelheim, Celltrion, Corrona, Crescendo, Genentech/Roche, GSK, Janssen, Eli Lilly \& Co., Merck, Novartis, Pfizer, Regeneron, Samsung, Sandoz, Sanofi, and UCB. LG is a member of an institution that received research funding for the present study; a consultant for AbbVie, BMS, Genentech/Roche, Janssen, Eli Lilly \& Co., Novartis, Pfizer, and UCB; and a member of the executive committee of the Outcome Measures in Rheumatology initiative. GRB is a member of an institution that received research funding from Sanofi and Regeneron Pharmaceuticals, Inc., for the present study. CWJP, SG, YL, HvH, and MR are employees of and shareholders in Sanofi. TK, CIC, and JVA are employees of and shareholders in Regeneron Pharmaceuticals, Inc. EKM is a shareholder of Pfizer Inc., and Regeneron Pharmaceuticals, Inc., and an employee of Regeneron Pharmaceuticals, Inc.

\section{Publisher's Note}

Springer Nature remains neutral with regard to jurisdictional claims in published maps and institutional affiliations.

\section{Author details}

${ }^{1}$ Stanford University, Palo Alto, CA, USA. ${ }^{2}$ Sorbonne Universités, UPMC Université Paris 6, GRC-UPMC 08 (EEMOIS), Paris, France. ${ }^{3}$ Department of Rheumatology, Assistance publique - Hôpitaux de Paris, Pitié Salpêtrière Hospital, Paris, France. ${ }^{4}$ Sanofi, Guildford, UK. ${ }^{5}$ Regeneron Pharmaceuticals, Inc., 777 Old Saw Mill River Road, Tarrytown, NY 10591-6707, USA. 'Sanofi, Paris, France. ${ }^{7}$ Sanofi, Bridgewater, NJ, USA. ${ }^{8}$ Charité - University Medicine, Berlin, Germany. ${ }^{9}$ Present Address: ViiV Healthcare, Brentford, UK. ${ }^{10}$ Present Address: Celgene, Summit, NJ, USA. 


\section{Received: 6 July 2017 Accepted: 30 April 2018}

Published online: 19 June 2018

\section{References}

1. Schaible HG. Nociceptive neurons detect cytokines in arthritis. Arthritis Res Ther. 2014;16:470.

2. Steiner G, Tohidast-Akrad M, Witzmann G, Vesely M, Studnicka-Benke A, Gal A, Kunaver M, Zenz P, Smolen JS. Cytokine production by synovial T cells in rheumatoid arthritis. Rheumatology (Oxford). 1999;38:202-13.

3. Matsumoto T, Tsurumoto T, Shindo H. Interleukin-6 levels in synovial fluids of patients with rheumatoid arthritis correlated with the infiltration of inflammatory cells in synovial membrane. Rheumatol Int. 2006;26:1096-100.

4. Sugiyama E, Kuroda A, Hori F, Hori T, Taki H, Arai N, Kobayashi M. Serum interleukin-6 level is a sensitive parameter of disease activity in rheumatoid arthritis. J Clin Rheumatol. 1995;1:93-8.

5. Dayer JM, Choy E. Therapeutic targets in rheumatoid arthritis: the interleukin-6 receptor. Rheumatology (Oxford). 2010;49:15-24.

6. Genovese MC, Fleischmann R, Kivitz AJ, Rell-Bakalarska M, Martincova R, Fiore S, Rohane P, van Hoogstraten H, Garg A, Fan C, et al. Sarilumab plus methotrexate in patients with active rheumatoid arthritis and inadequate response to methotrexate: results of a phase III study. Arthritis Rheumatol. 2015:67:1424-37.

7. Salliot C, van der Heijde D. Long-term safety of methotrexate monotherapy in patients with rheumatoid arthritis: a systematic literature research. Ann Rheum Dis. 2009;68:1100-4.

8. Nikiphorou E, Negoescu A, Fitzpatrick JD, Goudie CT, Badcock A, Ostor AJ, Malaviya AP. Indispensable or intolerable? Methotrexate in patients with rheumatoid and psoriatic arthritis: a retrospective review of discontinuation rates from a large UK cohort. Clin Rheumatol. 2014;33:609-14.

9. Lee SJ, Chang H, Yazici Y, Greenberg JD, Kremer JM, Kavanaugh A. Utilization trends of tumor necrosis factor inhibitors among patients with rheumatoid arthritis in a United States observational cohort study. J Rheumatol. 2009;36:1611-7.

10. Soliman MM, Ashcroft DM, Watson KD, Lunt M, Symmons DP, Hyrich KL. Impact of concomitant use of DMARDs on the persistence with anti-TNF therapies in patients with rheumatoid arthritis: results from the British Society for Rheumatology Biologics Register. Ann Rheum Dis. 2011;70:583-9.

11. Strand V, Kosinski M, Chen Cl, Joseph G, Rendas-Baum R, Graham NM, van Hoogstraten H, Bayliss M, Fan C, Huizinga T, et al. Sarilumab plus methotrexate improves patient-reported outcomes in patients with active rheumatoid arthritis and inadequate responses to methotrexate: results of a phase III trial. Arthritis Res Ther. 2016;18:198.

12. Fleischmann R, Castelar-Pinheiro G, Brzezicki J, Hrycaj P, Lin Y, van Adelsberg J, Graham N, van Hoogstraten H, Bauer D, Burmester G. Efficacy and safety of sarilumab in combination with Csdmards in patients with active rheumatoid arthritis who were inadequate responders or intolerant of anti-TNF therapy: results from a phase 3 study [abstract 970]. Arthritis Rheumatol. 2015;67(Suppl 10).

13. Strand V, Reaney M, Chen Cl, Proudfoot CW, Guillonneau S, Bauer D, Mangan E, Graham NM, van Hoogstraten H, Lin Y, et al. Sarilumab improves patient-reported outcomes in rheumatoid arthritis patients with inadequate response/intolerance to tumour necrosis factor inhibitors. RMD Open. 2017; 3:e000416.

14. Burmester $G$, Lin $Y$, Patel $R$, van Adelsberg J, Mangan EK, Graham NMH, van Hoogstraten H, Bauer D, Ignacio Vargas J, Bong Lee E. Efficacy and safety of sarilumab monotherapy versus adalimumab monotherapy for the treatment of patients with active rheumatoid arthritis (MONARCH): a randomised, double-blind, parallel-group phase III trial. Ann Rheum Dis. 2017;76:840-7.

15. van der Elst K, Meyfroidt S, De Cock D, De Groef A, Binnard E, Moons P, Verschueren $P$, Westhovens $R$. Unraveling patient-preferred health and treatment outcomes in early rheumatoid arthritis: a longitudinal qualitative study. Arthritis Care Res (Hoboken). 2016;68:1278-87.

16. Gossec L, Dougados M, Rincheval N, Balanescu A, Boumpas DT, Canadelo S, Carmona L, Daures JP, de Wit M, Dijkmans BA, et al. Elaboration of the preliminary Rheumatoid Arthritis Impact of Disease (RAID) score: a EULAR initiative. Ann Rheum Dis. 2009;68:1680-5.

17. Flurey CA, Morris M, Richards P, Hughes R, Hewlett S. It's like a juggling act: rheumatoid arthritis patient perspectives on daily life and flare while on current treatment regimes. Rheumatology (Oxford). 2014;53:696-703.
18. Cutolo M, Kitas GD, van Riel PL. Burden of disease in treated rheumatoid arthritis patients: going beyond the joint. Semin Arthritis Rheum. 2014;43:479-88.

19. Ostlund G, Bjork M, Thyberg I, Thyberg M, Valtersson E, Stenstrom B, Sverker A. Emotions related to participation restrictions as experienced by patients with early rheumatoid arthritis: a qualitative interview study (the Swedish TIRA project). Clin Rheumatol. 2014;33:1403-13.

20. Gossec L, Dougados M, Dixon W. Patient-reported outcomes as end points in clinical trials in rheumatoid arthritis. RMD Open. 2015;1:e000019.

21. Food and Drug Administration. Guidance for Industry: Patient-reported outcome measures: use in medical product development to support labeling claims. 2009. https://www.fda.gov/downloads/drugs/guidances/ ucm193282.pdf. Accessed 23 Feb 2017.

22. Felson DT, Anderson JJ, Boers M, Bombardier C, Chernoff M, Fried B, Furst D, Goldsmith C, Kieszak S, Lightfoot R, et al. The American College of Rheumatology preliminary core set of disease activity measures for rheumatoid arthritis clinical trials. Arthritis Rheum. 1993;36:729-40.

23. Ware Jr JE, Kosinski M, Bjorner JB, Turner-Bowker D, Maruish ME. User's manual for the SF-36v2 $2^{\text {TM }}$ Health Survey. 2nd ed. Lincoln, RI: Quality Metric; 2007.

24. Cella D, Yount S, Sorensen M, Chartash E, Sengupta N, Grober J. Validation of the Functional Assessment of Chronic Illness Therapy Fatigue Scale relative to other instrumentation in patients with rheumatoid arthritis. J Rheumatol. 2005;32:811-9.

25. Vliet Vlieland TP, Zwinderman AH, Breedveld FC, Hazes JM. Measurement of morning stiffness in rheumatoid arthritis clinical trials. J Clin Epidemiol. 1997; 50:757-63.

26. Gossec L, Paternotte S, Aanerud GJ, Balanescu A, Boumpas DT, Carmona L, de Wit M, Dijkmans BA, Dougados $M$, Englbrecht $M$, et al. Finalisation and validation of the rheumatoid arthritis impact of disease score, a patientderived composite measure of impact of rheumatoid arthritis: a EULAR initiative. Ann Rheum Dis. 2011;70:935-42.

27. Osterhaus JT, Purcaru O, Richard L. Discriminant validity, responsiveness and reliability of the rheumatoid arthritis-specific Work Productivity Survey (WPSRA). Arthritis Res Ther. 2009;11:R73.

28. Wells GA, Tugwell P, Kraag GR, Baker PR, Groh J, Redelmeier DA. Minimum important difference between patients with rheumatoid arthritis: the patient's perspective. J Rheumatol. 1993:20:557-60.

29. Schiff M, Weinblatt ME, Valente R, van der Heijde D, Citera G, Elegbe A, Maldonado M, Fleischmann R. Head-to-head comparison of subcutaneous abatacept versus adalimumab for rheumatoid arthritis: two-year efficacy and safety findings from AMPLE trial. Ann Rheum Dis. 2014;73:86-94.

30. Kremer JM, Blanco R, Brzosko M, Burgos-Vargas R, Halland AM, Vernon E, Ambs P, Fleischmann R. Tocilizumab inhibits structural joint damage in rheumatoid arthritis patients with inadequate responses to methotrexate: results from the double-blind treatment phase of a randomized placebocontrolled trial of tocilizumab safety and prevention of structural joint damage at one year. Arthritis Rheum. 2011;63:609-21.

31. Strand V, Boers M, Idzerda L, Kirwan JR, Kvien TK, Tugwell PS, Dougados M. It's good to feel better but it's better to feel good and even better to feel good as soon as possible for as long as possible: response criteria and the importance of change at OMERACT 10. J Rheumatol. 2011:38:1720-7.

32. Dworkin RH, Turk DC, Wyrwich KW, Beaton D, Cleeland CS, Farrar JT, Haythornthwaite JA, Jensen MP, Kerns RD, Ader DN, et al. Interpreting the clinical importance of treatment outcomes in chronic pain clinical trials: IMMPACT recommendations. J Pain. 2008;9:105-21.

33. Lubeck DP. Patient-reported outcomes and their role in the assessment of rheumatoid arthritis. PharmacoEconomics. 2004:22:27-38.

34. Dougados M, Brault Y, Logeart I, van der Heijde D, Gossec L, Kvien T. Defining cut-off values for disease activity states and improvement scores for patient-reported outcomes: the example of the Rheumatoid Arthritis Impact of Disease (RAID). Arthritis Res Ther. 2012;14:R129.

35. Krishnan E, Tugwell P, Fries JF. Percentile benchmarks in patients with rheumatoid arthritis: Health Assessment Questionnaire as a quality indicator (QI). Arthritis Res Ther. 2004:6:R505-13.

36. Webster K, Cella D, Yost K. The Functional Assessment of Chronic Illness Therapy (FACIT) Measurement System: properties, applications, and interpretation. Health Qual Life Outcomes. 2003;1:79.

37. Strand V, Rentz AM, Cifaldi MA, Chen N, Roy S, Revicki D. Health-related quality of life outcomes of adalimumab for patients with early rheumatoid arthritis: results from a randomized multicenter study. J Rheumatol. 2012;39:63-72. 
38. Gabay C, Emery P, van Vollenhoven R, Dikranian A, Alten R, Pavelka K, Klearman M, Musselman D, Agarwal S, Green J, et al. Tocilizumab monotherapy versus adalimumab monotherapy for treatment of rheumatoid arthritis (ADACTA): a randomised, double-blind, controlled phase 4 trial. Lancet. 2013;381:1541-50.

39. Rendas-Baum R, Bayliss M, Kosinski M, Raju A, Zwillich SH, Wallenstein GV, Koncz T. Measuring the effect of therapy in rheumatoid arthritis clinical trials from the patient's perspective. Curr Med Res Opin. 2014;30:1391-403.

40. Kirwan JR, de Wit MP, Bingham CO 3rd, Leong A, Richards P, Tugwell P, Voshaar M, Commentary GL. Patients as partners: building on the experience of outcome measures in rheumatology. Arthritis Rheumatol. 2016;68:1334-6

41. da Silva JA, Phillips S, Buttgereit F. Impact of impaired morning function on the lives and well-being of patients with rheumatoid arthritis. Scand J Rheumatol Suppl. 2011;125:6-11.

42. Mittendorf T, Dietz B, Sterz R, Cifaldi MA, Kupper H, von der Schulenburg $J \mathrm{M}$. Personal and economic burden of late-stage rheumatoid arthritis among patients treated with adalimumab: an evaluation from a patient's perspective. Rheumatology (Oxford). 2008;47:188-93.

43. Koike T, Harigai M, Ishiguro N, Inokuma S, Takei S, Takeuchi T, Yamanaka H, Haruna S, Ushida N, Kawana K, et al. Safety and effectiveness of adalimumab in Japanese rheumatoid arthritis patients: postmarketing surveillance report of 7740 patients. Mod Rheumatol. 2014;24:390-8.

Ready to submit your research? Choose BMC and benefit from:

- fast, convenient online submission

- thorough peer review by experienced researchers in your field

- rapid publication on acceptance

- support for research data, including large and complex data types

- gold Open Access which fosters wider collaboration and increased citations

- maximum visibility for your research: over $100 \mathrm{M}$ website views per year

At BMC, research is always in progress.

Learn more biomedcentral.com/submissions 